\title{
"Gravitron" Assisted Pull-Up Machines in Strength Building as Part of Physical Education Class in the Senior Years of Secondary School
}

\author{
Dorontsev A.V. \\ Astrakhan State Medical University \\ Astrakhan, Russia \\ aleksandr.doroncev@ rambler.ru
}

\author{
Morozova O.V. \\ Astrakhan State University \\ Astrakhan, Russia \\ ov-fomina@yandex.ru
}

\author{
Ermolina N.V. \\ Astrakhan State University \\ Astrakhan, Russia \\ tomara-72_64@mail.ru
}

\begin{abstract}
In order to meet the State Educational Standard for Secondary Schools in the Russian Federation, a comprehensive test investigating physical fitness in senior students was conducted. The sample consisted of male youth attending Astrakhan secondary schools. This test showcased that physical fitness in said students was underdeveloped. By using the weight machines, "Gravitron" assisted pull-up machine to be exact, the students were able to significantly improve their fitness and strength building capacities in order to prepare for the GTO pull-up tests on a horizontal bar. The research materials for the study were physical fitness test scores obtained from the secondary school students in Astrakhan (Russia) along with medical commission reports. In order to assess physical fitness in said sample, the students were asked to perform pull-ups on a horizontal bar. The calculations were computed using Statistica 10 analytics software package (USA) and its applications. The correlation analysis was performed applying the Pearson correlation coefficient. The PE curriculum for the experimental group introduced obligatory pull-ups on a horizontal bar. As a result, the strength building capacity of said students increased significantly over 6 months doing this exercise. The results of this study prove the effectiveness of using the "Gravitron" assisted pull-up machine (Russia) in PE classes in senior school which facilitates higher physical fitness scores when performing pullups on a horizontal bar.
\end{abstract}

Keywords-physical education in schools; senior students; strength building; assisted pull-up machine.

\section{INTRODUCTION}

The State Educational Standard for Secondary Schools in the Russian Federation provides for a comprehensive physical training program, sports activities, and negative attitude towards any bad habits and addictions [2,3,4]. The methodology accounting for PE classes' curriculum in schools is an intrinsic part of effective strength building [6]. The previous studies $[1,7,8,9,10,12]$ emphasize the fact that the school and university students not only lack physical fitness but also get sick more often. In their turn, the affected regulatory and self-adjusting mechanisms can cause pathological changes in the body $[13,15,16,17,20,21,22$, 23]. Sports activities [11, 14, 18, 19] and performing the check-up exercises which necessitate fulfilling the GTO tests (the all-Russian physical culture training program "Ready for Labor and Defence") should be the focus of PE classes [5]. In this regard, the "Gravitron" assisted pull-up fitness machine (Russia) was tested in PE classes in senior school, its purpose being to help the students build strength.

\section{ReseARCh Methodology}

The research material was the data obtained through the check-up strength testing conducted among the senior students (grades 10 and 11) in the secondary school №6, Astrakhan (Russia). The sample consisted of 29 male students who were not excused from participation in physical education for medical reasons. In order to assess physical fitness in said sample, students were asked to perform pull-ups on a horizontal bar. The mathematical calculations were enabled using Statistica 10 analytics software package (USA) and its applications. The correlation analysis was performed applying the Pearson correlation coefficient.

\section{RESULTS}

To exemplify how the physical fitness can be assessed, a "pull-ups on a horizontal bar" test was carried out. The results thereof showcased that the majority of the male students in Astrakhan secondary schools had difficulties performing this check-up test. In course of the study, two sample groups were formed. Both were comprised of male students (10th and 11th school years) attending the secondary school №6, Astrakhan (Russia). All sample students had had their annual medical checkup and, being medically suitable, were allowed to participate in PE classes. The PE curriculum of the experimental group $\left(\mathrm{n}_{1}-14\right)$ included pull-ups on the "Gravitron" assisted pull-up machine, whereas the control 
group $\left(n_{2}-15\right)$ was not required to perform those exercises. The initial stage of the study did not display whether there were any major mean value differences between the control group and the experimental one, the mean value amounting to $6,10 \pm 1,20$ repetitions. It should be however noted that this study did not include scores obtained from 2 students who were overweight and performed 0 pull-ups on the horizontal bar. Scores of two more students who had "Junior Athlete" ranks in gymnastics and boxing were excluded from the study as well. They did 22 and 18 repetitions, respectively. A set of strength-building exercises using the assisted pull-up "Gravitron" machine was adopted during the study:

- Parallel-grip pull-ups (3 sets of 8-10 repetitions);

- Neutral-grip chin-ups on a straight bar (3 sets of 10-12 repetitions);

- Behind-the-neck pull-ups on a curl bar (3 sets of 8-10 repetitions);

\section{— Chin-ups on a curl bar (3 sets of 10-12 repetitions).}

The recovery time between sets was determined individually - that was the time within which the heart rate dropped to 130 heartbeats per minute, being the 2 nd minute of rest. Upon completing all the given repetitions, a counterweight could be attached if needed adding $5 \mathrm{~kg}$ each time.

When using the "Gravitron" assisted pull-up machine, special attention was paid to how the exercise was performed. Students were not approved of:

— tilting their pelvis forward;

- having an excessive curve in the spine when performing the final part of the exercise;

- performing the exercise in a rough, abrupt manner;

- showing muscle imbalance in arms;

— not fixing their hands on the bar (grips) properly.

While performing the exercise, the arm angle was controlled. The students learned using the lats and the subscapularis muscles.

Thereafter, the dynamic changes and their fluctuations throughout the school year were assessed. The fitness scores improved significantly in the middle of the second term (hence, after 7 months) and amounted to $8.20 \pm 1.20 ; \mathrm{p}<0.05$; $\mathrm{r}=0.421$. The best horizontal bar pull-up performance scores amounted to $8.80 \pm 1.20 ; \mathrm{p}<0.05 ; \mathrm{r}=0.434$, being the 9th month of doing this exercise. The results observed at the end of the school year indicated that the fitness scores had reached their plateau. The control group $\left(\mathrm{n}_{2}-15\right)$ exhibited no significant improvements performing high bar pull-ups during the study.

\section{CONCLUSION}

Thus, the results confirm that implementing of the "Gravitron" assisted pull-up machine show positive results when applied in PE class in secondary school. The said exercise machine is very flexible in terms of adjusting the strength-building exercises to individual needs which is needed to meet personal health requirements. This aspect allowed not only to develop strength in students but as well to teach them proper and efficient exercise techniques. Hence, the exercises tested using the "Gravitron" assisted pull-up machine do arguably have a positive impact on strength building. At the same time, the ability to adjust the exercises to accommodate personal health requirements proves that the proposed method is reasonable and well-balanced.

\section{References}

[1] Dorontsev, A.V., Kozlyatnikov O.A. Characteristics and structure of morbidity rate in various groups of school students in Astrakhan Oblast. Scientific notes of P.F. Lesgaft University. 2014, 11 (117). pp. 46-49.

[2] "Social and Economic Development of the Astrakhan Oblast 2017" Report made by Astrakhan Oblast state agency Center for Social and Economic Monitoring and Analysis. URL: http://www.astrobl.ru

[3] Kostyuk, A.P. Organizational and pedagogical conditions needed to facilitate the developing the State Educational Standard for Secondary Schools in regions. Candidate's thesis. Kaliningrad. 1999, 154.

[4] "Astrakhan Oblast and its development" agenda (revisions from 14.08.2017). URL: http://base.consultant.ru

[5] Chichkova, M.A., Svetlichkina A.A. Circular system adaptation to the exercises in hearing-impaired subjects. Astrakhan Medical Journal. 2016, vol. 4, pp. 64-71.

[6] Chichkova, M.A., Svetlichkina A.A., Dorontes A.V. Adaptive sports and their influence on the circulatory system reserve rates in subjects with sensorineural hearing loss, degrees I and II. Human. Sports. Medicine. 2018, vol. 18(4), pp. 117-122.11.

[7] Claessens, M., Claessens C., Claessens P. et al. Importance of determining the percentage body fat in endurance-trained athletes. Indian Heart J. 2000, 52, pp. 307-314.

[8] Garthe, Ina, TrulsRaastad, JorunnSundgot-Borgen. Effect of Weight Loss on Body Composition and Performance in Elite Athletes. Human Kinetics Journals. 2011, vol. 21(5), pp. 426-435.

[9] Kazemi, Mohsen, Judith Waalen, Christopher Morgan, Anthony R. White. A Profile Of Olympic Taekwondo Competitors. J Sports Sci Med. 2006, 5(CSSI), pp. 114-121.

[10] Kenneth, J.E., Stacey B.J., Chertow G.M. Bioelectrical impedance methods in clinical research: a follow-up to the NIH technology assessment conference. Nutrition. 1999, 15, pp. 874-880.

[11] Kotler, D.P., Burastero S., Wang J., Pierson R.N. Prediction of body cell mass, fat-free mass, and total body water with bioelectrical impedance analysis: effects of race, sex, and disease. Am J ClinNutr. 1996, 64, pp. 489-497.

[12] Ozcakar, L. Comparative body fat assessment in elite footballers. British Journal of Sports Medicine. 2003, 37, pp. 278-279.

[13] Salci, Yasar. The metabolic demands and ability to sustain work outputs during kickboxing competitions. International Journal of Performance Analysis in Sport. 2015, vol. 15(1), pp. 39-52.

[14] Salvatore, Chiodo. Effects of Official Taekwondo Competitions on AllOut Performances of Elite Athletes. The Journal of Strength \& Conditioning Research. 2011, vol. 25(2), pp.334-339.

[15] Shafer, K. J. Validity of segmental multiple-frequency bioelectrical impedance analysis to estimate body composition of adults across a range of body mass indexes. Nutrition. 2009, 25, pp. 25-32.

[16] Sun, G. Comparison of multifrequency bioelectrical impedance analysis with dual-energy X-ray absorption for assessment of percentage body fat in a large, healthy population. Am J ClinNutr. 2005, 81, pp. 4-8.

[17] Vardar, Selma Arzu. The Relationship Between Body Composition and Anaerobic Performance of Elite Young Wrestlers. J Sports Sci Med. 2007, 6(CSSI-2), pp. 34-38.

[18] Dorontsev A.V., Zinchuk N.A., Rybnikova O.L., Fedorova T.A. Factors of trumatism and regulatory-adaptive status disorder among people going in for crossfit. The Russian Journal of Physical Education and Sport. 2018, 13(2), pp. 188-190. DOI: 10.14526/02_2018_331.

[19] Kuznetsova Z.M., Kuznetsov S.A., Ovchinnikov Yu.D., Golovko P.V. Analysis of the morphological-functional indices connection degree in 
[20] Yoon, Jaeryang. Physiological Profiles of Elite Senior Wrestlers. Sports

throwing among athletes. The Russian Journal of Physical Education and Sport. 2018, 13(2), pp. 44-50. DOI: 10.14526/02_2018_308.
Medicine. 2002, vol. 32(4), pp. 225-233. 